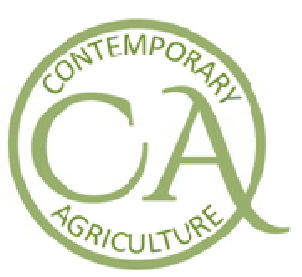

\author{
sciendo \\ Contemporary Agriculture \\ Serbian Journal of Agricultural Sciences \\ Faculty of Agriculture, University of Novi Sad, Serbia \\ www.contagri.info
}

\title{
ANTIOXIDANT ACTIVITY AND POLYPHENOLIC PROFILE OF WALNUT (JUGLANS REGIA L.) GREEN HUSKS AND LIQUEURS
}

\author{
DIJANA KULAČANIN ${ }^{1 *}$, SANDRA BIJELIĆ ${ }^{1}$, JOVANA ŠUĆUR ${ }^{2}$, \\ BORIVOJE BOGDANOVIĆ ${ }^{\prime}$, SEZAI ERCISLI ${ }^{3}$, ĐORĐE MALENČIĆ \\ ${ }^{1}$ University of Novi Sad, Faculty of Agriculture, Department of Fruit Science, Viticulture, Horticulture and \\ Landscape Architecture, Trg Dositeja Obradovića 8, 21000 Novi Sad, Serbia \\ ${ }^{2}$ University of Novi Sad, Faculty of Agriculture, Department of Field and Vegetable Crops, Trg Dositeja \\ Obradovića 8, 21000 Novi Sad, Serbia \\ ${ }^{3}$ Atatürk University, Faculty of Agriculture, Department of Horticulture, 25240 Erzurum, Turkey \\ *Corresponding author: dijana.kulacanin@gmail.com
}

\begin{abstract}
SUMMARY
The beneficial effects of walnuts and walnut products on human health, due primarily to their rich polyphenolic content, have been appreciated as an empirical fact for centuries. The purpose of this study is to determine the polyphenolic contents of liqueurs made from the walnut selections 'Rasna' and 'Sava' and the walnut cultivar 'Šampion' (all harvested at three different times), as well as the polyphenolic contents of their green husks. The walnut liqueurs were prepared according to two traditional recipes using young walnut fruits. The highest antioxidant capacity was recorded in the liqueur made from the 'Rasna' walnut selection (89.94\%), whereas the highest contents of phenols ( $83.28 \mathrm{mg} \mathrm{GAE} / \mathrm{g} \mathrm{FW),} \mathrm{flavonoids}(0.83 \mathrm{mg} \mathrm{QE} / \mathrm{g} \mathrm{FW}$ ) and proanthocyanidins were found in the liqueur made from the 'Šampion' cultivar (14.75 mg CE/g FW). The youngest 'Rasna' walnuts, harvested at the first experimental time point, exhibited the highest phenolic and tannin contents, whereas the highest flavonoid content was observed in the 'Šampion' cultivar. The biochemical results obtained indicate a decrease in the polyphenolic content of walnut fruits with their growth and development. Moreover, the polyphenolic profiles of the walnut liqueurs considered were found to be greatly affected by the method of preparation and the cultivar/selection of walnuts.
\end{abstract}

Key words: flavonoids, phenols, liqueur, proanthocyanidin, green husks

Abbreviations: TP - total phenols; GAE - gallic acid equivalents; FW - fresh weight; PVPP polyvinylpolypyrrolidone; QE - quercetin equivalent; PA - proanthocyanidins; CE - catechin equivalents; DPPH radicals - 2,2-diphenyl-1-picrylhydrazyl radicals.

\section{INTRODUCTION}

Over the course of centuries, walnut liqueurs have been found to exert beneficial effects on human health. As little or no pesticides are used in walnut production, walnut liqueurs can be considered healthy for containing little or no pesticide residues. Compared to other fruit crops, the walnut is highly susceptible to oxidation reactions, which is indicative of the increased presence of antioxidant compounds inhibiting lipid autoxidation (Čađenović et al., 2012). Walnut fruits, bark, roots, leaves, cotyledons, meats and oil are used for medicinal purposes (Stampar et al., 2005; Upadhyay et al., 2010). The Junglandaceae family, Juglans regia, is referred to as the royal walnut family for its oxidative stress-relieving properties (Shah et al., 2015). Norouzi et al. (2013) argue that consuming walnuts is the easiest way to improve health. A number of studies have suggested that nutrition is of crucial importance to the 
prevention of serious diseases such as congenital defects, coronary diseases, cancer and cataracts (Taha \& AlWadaan, 2011; Čađenović et al., 2012; Noumi et al., 2012; Shah et al., 2015). Juglans regia fruits are used in traditional medicine for treating respiratory diseases, skin and bone disorders, anorexia, diarrhoea, stomach-ache, scrofula, various endocrine diseases, infectious diseases, and cancer. Walnuts also have wide applications in the cosmetic and pharmaceutical industries (Stampar et al., 2005, Upadhyay et al., 2010., Taha \& Al-Wadaan, 2011., Shah et al., 2015). J. regia bark and leaves are highly therapeutic (Noumi et al., 2012). In some European countries, especially in Portugal, dry walnut leaves are used for infusion therapy (Amaral et al., 2004). In the Middle East, walnuts are added, individually or in combination with other fruits, to traditional dainties such as Ma'moul (Taha \& Al-Wadaan, 2011). In Modena, Italy, the liqueur made from unripe walnuts (namely the nocino liqueur) in used as an after-dinner drink (Alamprese et al. 2005). Phenolic compounds are one of the most active antioxidant compounds (Saeed et al., 2015). Phenols actively partake in the physiological processes of walnut fruit growth and development, exerting various impacts on walnut fruits before and after harvest. Catanzaro et al. (2018) suggest that the phenolic content of walnuts is conditioned by both genetic and environmental factors, whereas Wianowska et al. (2016) report that the flavonoid and phenolic contents of walnut extracts depend on the J. regia cultivars used. Cosmulescu et al. (2010) conclude that the phenolic content of walnut green husks decreases significantly with walnut maturation. Solar et al. (2006) assert that the phenolic content of walnuts depends on their developmental stage. MikulicPetkovsek et al. (2011) argue that total phenols essentially contribute to disease resistance. Phenolic contents vary in different parts and growth phases of the Persian walnut: total phenols increase in early and mid summer, followed by a decrease in late summer and a new increase before the harvest period (Cosmulescu \& Trandafir, 2011). Stampar et al. (2005) identified a total of 13 phenolic compounds in walnut husks. Walnut green husks are rich in phenolic compounds such as juglone (Colarič et al., 2005). Juglone (5-Hydroxy 1,4-naphtoquinone) is a specific phenolic compound that exists only in walnuts, especially in green walnut parts such as leaves, husks, stems and roots. Juglandin has exhibited cytotoxicity to different types of breast, lung and skin cancer cells (Catanzaro et al., 2018). Phenols impart a bitter yet pleasant taste to walnut liquors (Stampar et al., 2005). The purpose of this study is to determine the polyphenolic contents of liqueurs made from the walnut selections 'Rasna' and 'Sava' and the walnut cultivar 'Šampion' (all harvested at three different times), as well as the polyphenolic contents of their green husks.

\section{MATERIAL AND METHODS}

\section{Plant material}

The walnut cultivar 'Šampion' and selections 'Rasna' and 'Sava' were enrolled in this study. The walnuts considered were harvested at three different times in 2017: $5^{\text {th }}$ May, $25^{\text {th }}$ May and $5^{\text {th }}$ September.

\section{Preparation of walnut ethanol extract}

Green husks were removed from the fruits and chopped in small pieces. A plant mass of $0.5 \mathrm{~g}$ was extracted using $40 \%$ ethanol. After $24 \mathrm{~h}$, the filtered sample was prepared for analysis. The dehusking method employed was the same for all the three samples examined.

\section{Preparation of walnut liqueur}

The walnut liqueur recipe consists of a small number of ingredients: $140 \mathrm{~g}$ of young walnut fruits, $250 \mathrm{~g}$ of sugar, 50 $\mathrm{g}$ of honey, and $1 \mathrm{~L}$ of grape brandy per glass jar.

Fruits of all the walnut selections and cultivars considered were first harvested on $25^{\text {th }}$ May 2017. The fruits were then carefully washed with cold water and all the impurities were removed. Two different methods of liqueur preparation were used with each of the walnut cultivar and selections considered, thus resulting in a total of six different walnut liqueurs. The first method involved washing the walnut fruits, cutting off the peduncle and placing the whole fruits into a previously well-washed glass jar. However, the second method involved cutting the fruits into halves with a sharp knife. The prepared fruits (140 g) were placed into six jars with a capacity of $1.5 \mathrm{~kg}$, after which $250 \mathrm{~g}$ of sugar was added to each. Cellophane covers were placed over the jar tops to avoid contact with the metal lid during the process. The jars were sealed and left in a sunny place over a period of 40 days (with regular shaking every two days). After 40 days, a litre of grape brandy and $50 \mathrm{~g}$ of honey were added to each jar, after which new cellophane covers were placed over the jar tops and the jars were tightly sealed with metal lids. The liqueurs thus prepared were left in a dark room at room temperature. The jars were occasionally shaken to avoid honey settling. Following another 40 days, the liqueurs were ready for consumption and analysis. 


\section{Determination of the phenolic content of walnut extracts}

The concentration of total phenols (TPs) in the walnut extracts considered was determined spectrophotometrically using the "Folin-Ciocalteu" reagent (Hagerman et al., 2000). This method is based on measuring the reducing capacity of phenols and other compounds. The amount of TPs was calculated as the gallic acid equivalent, relative to the calibration curve of gallic acid standard solutions (covering the concentration range between 0.1 and $1.0 \mathrm{mg} / \mathrm{ml}$ ), and expressed as mg gallic acid equivalents/g fresh weight (mg GAE/g FW).

\section{Determination of the tannin content of walnut extracts}

In order to determine the tannin content of the walnut extracts considered, the method for determining the phenolic content was employed, but the samples used were obtained by the centrifugation $(10.000 \mathrm{x} \mathrm{g}, 10 \mathrm{~min})$ of the reaction mixture consisting of $0,1 \mathrm{~g}$ of polyvinylpolypyrrolidone (PVPP), $1 \mathrm{ml}$ of water and $1 \mathrm{ml}$ of the extract. After the removal of tannins by adsorption on an insoluble matrix (PVPP), the non-tannin phenolic content in the supernatant was determined. The tannin content of the samples was calculated from the difference between the content of total phenols and non-tannin phenolic compounds, and expressed as mg gallic acid equivalents/g fresh weight (mg GAE/g FW).

\section{Determination of the flavonoid content of walnut extracts}

The concentration of flavonoids was calculated as the quercetin equivalent $(\mathrm{QE})$, relative to the calibration curve of quercetin standard solutions, and expressed as mg quercetin equivalents/g fresh weight (mg QE/g FW) (Markham, 1989).

\section{Determination of the proanthocyanidin content of walnut extracts}

The concentration of proanthocyanidins (PA) in the walnut extracts considered was determined using a butanol- $\mathrm{HCl}$ assay (Sun et al., 1998). The aliquots of the prepared extracts $(0.5 \mathrm{ml})$ were placed into test tubes. After the addition of butanol- $\mathrm{HCl}$ reagent $(3 \mathrm{ml})$ and $2 \%$ ferric reagent $(0.1 \mathrm{ml})$, the test tubes were vortexed and placed in a boiling water bath for $60 \mathrm{~min}$. After cooling, the absorbance was recorded at $550 \mathrm{~nm}$ against a blank containing solvent $(0.5$ $\mathrm{ml}$ ) instead of the extract. The amount of proanthocyanidins was expressed as $\mathrm{mg}$ catehin equivalents/g fresh weight (mg CE/g FW).

\section{Determination of DPPH radical neutralization}

The spectrophotometric determination of the "scavenging" activity of these extracts was based on monitoring the transformation of DPPH radicals (2.2-diphenyl-1-picrylhydrazyl radicals) in a reduced (DPPH-H) form. The DPPH radical is purple and it has a maximum absorption at $517 \mathrm{~nm}$. Through reactions with antioxidants, it binds a hydrogen atom to its unpaired electron and thereby turns yellow. The DPPH assay was done according to the method of Lee et al. (1998).

\section{Statistical analysis}

The results obtained were statistically analysed using StatSoft (2017) and the analysis of variance (ANOVA). The parameter mean difference was set at a significance level of $0.01 \%$ using the Duncan's multiple range test. The results obtained are shown in Tables 1 and 2 .

\section{RESULTS AND DISCUSSION}

The biochemical composition of walnut green husks and the phenolic content of the walnut cultivar and selections considered are given in Table 1. The highest phenolic content of green husks was found in the selection 'Rasna' harvested at the $1^{\text {st }}$ experimental time point $(68.08 \mathrm{mg}$ GAE/g FW), whereas the lowest phenolic content of green husks was recorded in the selection 'Sava' harvested at the $3^{\text {rd }}$ experimental time point (17.50 mg GAE/g FW). The results obtained indicate that the concentration of polyphenols and their antioxidant activity decrease with walnut fruit ripening, with the exception of proanthocyanidins which increase with fruit ripening during the second harvest period ( $25^{\text {th }}$ May) and then decrease in the $3^{\text {rd }}$ harvested period. Moreover, it can be argued that the concentration of polyphenols depend on the walnut cultivar/selection. Wianowska et al. (2016) investigated the phenolic content of walnut green husks from different cultivars and seedlings. The concentration of phenols at harvest was in the range of 90.64- $117.707 \mathrm{mg} \mathrm{GAE} / \mathrm{g} \mathrm{FW}$. Ghasemi et al. (2011) report that the phenolic content of the 11 walnut cultivars examined ranged between 15.15 and $108.11 \mathrm{mg} \mathrm{GAE} / \mathrm{g} \mathrm{FW}$, whereas Jalili et al. (2012) report that the average phenolic content of the seven walnut extract considered ranged $23.40 \pm 0.89 \mathrm{mg} \mathrm{GAE} / \mathrm{g}$ FW. Oliveira et al. (2008) 
found that the total concentration of phenols in walnut extracts ranged from 32.61 to $74.04 \mathrm{mg} \mathrm{GAE} / \mathrm{g} \mathrm{FW}$, depending on the walnut cultivars used.

Table 1. Average concentrations of phenols, tannins, flavonoids and proanthocyanidins in walnut fruits harvested at three experimental time points $\left(1^{\text {st }}, 2^{\text {nd }}\right.$ and $\left.3^{\text {rd }}\right)$ and the DPPH-assay results

\begin{tabular}{|c|c|c|c|c|c|c|}
\hline $\begin{array}{l}\frac{\ddot{a}}{\tilde{a}} \\
\text { 苛 }\end{array}$ & 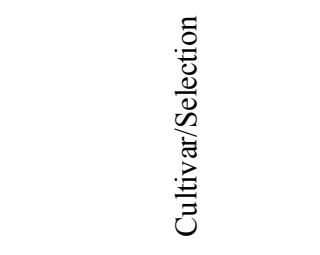 & 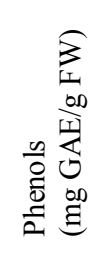 & 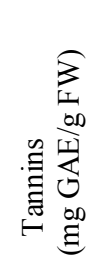 & 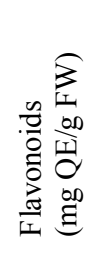 & 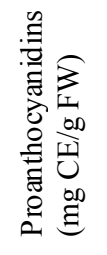 & $\begin{array}{l}\hat{d} \\
\frac{0}{a} \\
\hat{\frac{1}{0}}\end{array}$ \\
\hline 1. & 'Rasna' $1^{\text {st }}$ time point & $68.08^{a}$ & $63.18^{\mathrm{a}}$ & $2.92^{\mathrm{b}}$ & $32.40^{\mathrm{d}}$ & $88.25^{\mathrm{a}}$ \\
\hline 2. & 'Sava' $1^{\text {st }}$ time point & $62.64^{\mathrm{b}}$ & $59.00^{\mathrm{b}}$ & $3.70^{\mathrm{ab}}$ & $58.02^{\mathrm{b}}$ & $83.55^{\mathrm{b}}$ \\
\hline 3. & 'Šampion' $1^{\text {st }}$ time point & $66.74^{\mathrm{a}}$ & $58.73^{b}$ & $4.15^{\mathrm{a}}$ & $48.96^{\mathrm{c}}$ & $88.14^{\mathrm{a}}$ \\
\hline 4. & 'Rasna' $2^{\text {nd }}$ time point & $22.02^{\mathrm{de}}$ & $18.65^{\mathrm{e}}$ & $0.96^{\mathrm{cd}}$ & $53.52^{b}$ & $24.41^{\mathrm{de}}$ \\
\hline 5. & 'Sava' $2^{\text {nd }}$ time point & $25.86^{\mathrm{d}}$ & $22.74^{\mathrm{d}}$ & $1.32^{\mathrm{c}}$ & $74.38^{\mathrm{a}}$ & $32.26^{\mathrm{d}}$ \\
\hline 6. & 'Šampion' $2^{\text {nd }}$ time point & $33.75^{\mathrm{c}}$ & $29.54^{\mathrm{c}}$ & $1.21^{\mathrm{c}}$ & $76.38^{\mathrm{a}}$ & $49.11^{\mathrm{c}}$ \\
\hline 7. & 'Rasna' $3^{\text {rd }}$ time point & $24.23^{\mathrm{d}}$ & $19.86^{\mathrm{de}}$ & $0.47^{\mathrm{e}}$ & $23.39^{\mathrm{e}}$ & $15.34^{\mathrm{e}}$ \\
\hline 8. & 'Sava' $3^{\text {rd }}$ time point & $17.50^{\mathrm{f}}$ & $13.84^{\mathrm{f}}$ & $0.52^{\mathrm{e}}$ & $15.41^{\mathrm{f}}$ & $9.50^{\mathrm{f}}$ \\
\hline 9. & 'Šampion' $3^{\text {rd }}$ time point & $24.13^{\mathrm{e}}$ & $18.75^{\mathrm{e}}$ & $0.72^{\mathrm{d}}$ & $22.88^{\mathrm{e}}$ & $13.25^{\mathrm{ef}}$ \\
\hline
\end{tabular}

The highest concentration of tannins was found in the 'Rasna' green husks harvested at the first experimental time point $(63.18 \mathrm{mg} \mathrm{GAE} / \mathrm{g} \mathrm{FW})$, whereas the lowest tannin concentration was recorded in the 'Sava' green husks harvested at the $3^{\text {rd }}$ experimental time point $(13.75 \mathrm{mg}$ GAE/g FW). Chrzanowski et al. (2010) report a total tannin content of $237.4 \mathrm{mg} \mathrm{GAE} / \mathrm{g} \mathrm{FW}$ in walnut green husks, which is much higher than our results probably due to different harvest timings.

According to Wianowska et al. (2016), the flavonoid content of walnuts ranges from $0.280 \mathrm{mg} Q \mathrm{QE} / \mathrm{g} \mathrm{FW}$ to $2.570 \mathrm{mg}$ QE/g FW depending on the cultivar/seedling. The highest concentration of flavonoids was found in the 'Šampion' green husks harvested at the $1^{\text {st }}$ experimental time point ( $\left.4.15 \mathrm{mg} \mathrm{QE} / \mathrm{g} \mathrm{FW}\right)$, whereas the 'Rasna' green husks harvested at the $3^{\text {rd }}$ experimental time point were found to have the lowest concentration of flavonoids $(0.47 \mathrm{mg}$ $\mathrm{QE} / \mathrm{g} \mathrm{FW})$.

The highest concentration of proanthocyanidins was recorded in the 'Šampion' green husks harvested at the $2^{\text {nd }}$ experimental time point $(76.38 \mathrm{mg}$ of CE/g FW), i.e. in late May, and the lowest concentration of proanthocyanidins was observed in the 'Sava' green husks harvested at the $3^{\text {rd }}$ time point $(15.51 \mathrm{mg} \mathrm{CE} / \mathrm{g} \mathrm{FW})$. The antioxidant activity is directly proportional to the concentration of polyphenols (Malenčić et al., 2012).

The DPPH scavenging activity was the highest in the 'Rasna' green husks harvested at the $1^{\text {st }}$ experimental time point $(88.25 \%)$ and the 'Šampion' green husks harvested at the $1^{\text {st }}$ experimental time point $(88.14 \%)$. However, the lowest DPPH scavenging activity was recorded in the 'Sava' green husks harvested at the $3^{\text {rd }}$ experimental time point $(9.50 \%)$, suggesting that walnut fruits exhibit higher DPPH activity when harvested at the beginning of ripening. Different aqueous extracts of walnut (J. regia L.) green husks show antimicrobial activity and can be used as an easily affordable source of health-protective compounds (Pereira et al., 2007) and a protective system against pathogenic fungi (Ebrahimi et al., 2018). Alamprese et al. (2005) report than the antioxidant potential of walnut liqueur is directly correlated with the total content and characteristics of walnut phenols. The biochemical composition of the walnut liqueurs examined and the DPPH scavenging activity of the extracts are presented in Table 2 . 
Table 2. Average concentrations of total phenols, tannins, flavonoids and proanthocyanidins in the walnut liqueurs examined and the DPPH scavenging activity of the extracts

\begin{tabular}{|c|c|c|c|c|c|c|}
\hline 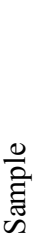 & 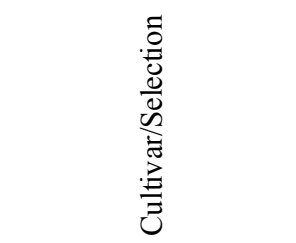 & 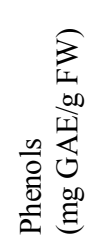 & 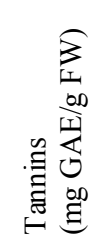 & 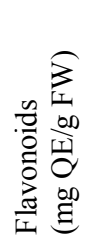 & 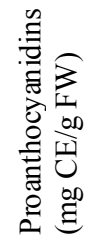 & $\begin{array}{l}\hat{0} \\
\frac{0}{2} \\
\stackrel{1}{0}\end{array}$ \\
\hline 1. & 'Rasna' whole fruits & $63.36^{\mathrm{c}}$ & $55.46^{\mathrm{c}}$ & $0.27^{\mathrm{e}}$ & $9.86^{\mathrm{c}}$ & $82.30^{\mathrm{ab}}$ \\
\hline 2. & 'Šampion' whole fruits & $74.24^{\mathrm{b}}$ & $64.80^{\mathrm{b}}$ & $0.83^{\mathrm{a}}$ & $14.75^{\mathrm{a}}$ & $68.17^{\mathrm{c}}$ \\
\hline 3. & 'Sava' whole fruits & $65.55^{\mathrm{c}}$ & $58.00^{\mathrm{bc}}$ & $0.41^{\mathrm{d}}$ & $11.26^{\mathrm{b}}$ & $79.77^{\mathrm{b}}$ \\
\hline 4. & 'Rasna' cut fruits & $73.45^{\mathrm{b}}$ & $64.62^{\mathrm{b}}$ & $0.64^{\mathrm{b}}$ & $9.64^{\mathrm{c}}$ & $89.94^{\mathrm{a}}$ \\
\hline 5. & ‘Šampion’ cut fruits & $83.28^{\mathrm{a}}$ & $71.54^{\mathrm{a}}$ & $0.51^{\mathrm{c}}$ & $11.58^{\mathrm{b}}$ & $82.52^{\mathrm{ab}}$ \\
\hline 6. & 'Sava' cut fruits & $72.46^{\mathrm{b}}$ & $64.34^{\mathrm{b}}$ & $0.88^{\mathrm{a}}$ & $9.82^{\mathrm{c}}$ & $77.86^{\mathrm{b}}$ \\
\hline
\end{tabular}

The highest phenolic content was found in the liqueur made from the cut 'Šampion' walnuts (83.28 mg GAE/g FW), whereas the lowest phenolic content was recorded in the liqueur made from the whole 'Rasna' walnuts $(63.36 \mathrm{mg}$ $\mathrm{GAE} / \mathrm{g} \mathrm{FW}$ ). The decisive effect of walnut cultivars on the phenolic content of walnut liqueurs was also argued by Jakopic et al. (2007), who determined higher phenolic concentrations in the liqueur prepared from the 'Franquette' cultivar than in that made from the 'Elit' cultivar. Jakopič el al. (2009) recorded changes in the phenolic content of walnuts in different solvents. In methanol, a phenolic content of $161.07 \mathrm{mg} \mathrm{GAE} / \mathrm{g} \mathrm{FW}$ was recorded in the 'Franquette' cultivar, compared to $148.98 \mathrm{mg} \mathrm{GAE} / \mathrm{g} \mathrm{FW}$ recorded in the 'Elit' cultivar. In ethanol, a phenolic content of $135.27 \mathrm{mg} \mathrm{GAE} / \mathrm{g} \mathrm{FW}$ was recorded in the 'Franquette' cultivar, compared to $126.20 \mathrm{mg}$ GAE/g FW observed in the 'Elit' cultivar.

In the present research, the highest tannin content was found in the liqueur made from the whole 'Šmpion' walnuts (71.54 mg GAE/100 g of dry material), whereas the lowest tannin content was recorded in the liqueur made from the whole 'Rasna' fruits (55.46 mg GAE/100 g of dry material). The highest flavonoid content was found in the liqueur made from the cut 'Sava' walnuts $(0.88 \mathrm{mg}$ QE/g FW) and whole 'Šampion' walnuts (0.83 mg QE/g FW), wheras the liqueur made from the whole 'Rasna' walnuts had the lowest flavonoid content $(0.27 \mathrm{mg}$ QE/g FW). The concentration of proanthocyanidins was the highest in the liqueur made from the whole 'Šampion' walnuts (14.75 $\mathrm{mg} \mathrm{CE} / \mathrm{g} \mathrm{FW}$ ), whereas the lowest proanthocyanidin concentration was found in the liqueur made from the whole 'Rasna' walnuts (9.86 mg CE/g FW), the cut 'Rasna' walnuts (9.64 mg CE/g FW) and the whole 'Sava' walnuts (9.82 $\mathrm{mg} \mathrm{CE} / \mathrm{g} \mathrm{FW}$ ).

The DPPH scavenging activity was the highest in the 'Rasna' selection (89.94\%) and the lowest in the 'Šampion' cultivar (68.17\%). Shah et al. (2015) argue that methanolic walnut extracts contain higher phenolic contents (94.39 \pm $5.63 \mathrm{mg} \mathrm{GAE} / \mathrm{gFW})$ than aqueous walnut extracts $(27.92 \pm 1.40 \mathrm{mg} \mathrm{GAE} / \mathrm{gFW})$. Furthermore, methanolic walnut extracts exhibit the highest antioxidant activity (EC50 of $0.250 \mathrm{mg} / \mathrm{ml})$, followed by water extracts (EC50 of 0.325 $\mathrm{mg} / \mathrm{ml})$ in the Fenton's reaction $(0.199 \pm 0.023$ and $2.991 \pm 0.740$, respectively).

\section{CONCLUSION}

The results obtained indicate that young walnut fruits are an important source of polyphenols (namely proanthocyanidine, tannin and flavonoid) and thus can be considered a functional food, especially in the form of liqueurs and other beverages. Concentrations of tannins, flavonoids, proanthocyanidines and phenols were found to be the highest in walnut liqueurs, particularly in the one made from walnut halves. However, the antioxidant activity and polyphenolic content of walnuts were found to decrease with their growth and development.

Acknowledgement: This research was partially supported by the Faculty of Agriculture, University of Novi Sad. 


\section{REFERENCES}

Alamprese C., Pompei C., Scaramuzzi F. (2005): Caracterization and antioxidative activity of nocino liqueur. Food Chemistry, 90(4): 495-502.

Amaral J.S., Seabra R.M., Andrade P.B., Valentão P., Pereira J.A., Ferreres F. (2004): Phenolic profile in the quality control of walnut (Juglans regia L.) leaves. Food Chemistry, 88(3): 373-379.

Catanzaro E., Greco G., Potenza L., Calcabrini C., Fimognari C. (2018): Natural products to fight cancer: a focus on Juglans regia. Journal List, Toxins (Basel), 10 (11): 469.

Chrzanowski G., Leszczyński B., Czerniewicz P., Sytykiewicz H., Matok H., Krzyżanowski R. (2010): Phenolic acids of walnut (Juglans regia L.). Herba Polonica, 57(2):22-29.

Colarič M., Veberič R., Solar A., Hudina M., Stampar F. (2005): Phenolic acids, syringaldehyde and juglone in fruits of different cultivars of Juglans regia L. Journal of Agricultural and Food Chemistry, 53(16): 6390-6396.

Cosmulescu S. \& Trandafir I. (2011): Variation of phenols content in walnut (Juglans regia L.). South Western Journal of Horticulture, Biology and Environment, 2(1): 25-33.

Cosmulescu S., Trandafir I., Achim G., Botu M., Baciu A., Gruia M. (2010): Phenolics of green husk in mature walnut fruits. Notulae Botanicae Horti Agrobotanici Cluj-napoca, 38 (1): 53-56.

Čađenović J., Milovanović M., Vlajković V. (2012): Healing properties of walnut. PONS Medicinal Journal, 10(1): 33-34.

Ebrahimi S., Jamei R., Nojoomi F., Zamanian Z. (2018): Persian walnut composition and its importance in human health International Journal of Enteric Pathogens, 6(1): 3-9.

Ghasemi K., Ghasemi Y., Ehteshamnia A., Mohammad S.N., Nabavi S.F., Ebrahimzadeh M. A., Pourmorad F. (2011): Influence of environmental factors on antioxidant activity, phenol and flavonoids contents of walnut (Juglans regia L.) green husks. Journal of Medicinal Plants Research, 5(7): 1128-1133.

Hagerman A., Harvey-Mueller I., Makhar H.P.S. (2000): Quantification of tannins in tree foliage. Joint FAO/IAEA division of nuclear techniques in food and agriculture animal production and health sub-programme, working document, Vienna pp: $1-26$.

Jakopic J., Colaric M., Veberic R., Hudina M., Solar A., Stampar F. (2007): How much do cultivar and preparation time influence on phenolics content in walnut liqueur? Food Chemistry, 104(1): 100-105.

Jakopič J., Veberič R., Štampar F. (2009): Extraction of phenolic compounds from green walnut fruits in different solvents Acta agriculturae Slovenica, 93(1): 11-15.

Jalili A., Reza H., Sadeghzade A., Alipour S. (2012): Reducing power and radical scavenging activities of phenolic extracts from Juglans regia hulls and shells. African Journal of Biotechnology, 11(37): 9040-9047.

Lee S.K., Mbwambo Z., Chung H., Luyengi L., Gamez E., Mehta R., Kinghorn A., Pezzuto J. (1998): Evaluation of the antioxidant potential of natural products. Combinatorial Chemistry \& High Throughoutput Screening, 1(1): 35-46.

Malenčić Đ., Cvejić J., Miladinović J., (2012): Polyphenol content and antioxidant properties of colored soybean seeds from central Europe. Journal of medicinal food, 15(1): 89-95.

Markham K.R. (1989): Methods in Plant Biochemistry. London, Academic Press, 16: 193-237.

Mikulic-Petkovsek A., Slatnar R., Veberic F., Stampar A., Solar A. (2011): Phenolic response in green walnut husk after the infection with bacteria Xanthomonas arboricola pv. juglandis. Physiological and molecular plant pathology, 76(3): $159-165$.

Norouzi R., Heidari S., Asgari- Sarcheshmeh M.A., Shahi- Garahlar A. (2013): Estimation of phenotypical and morphological differentiation among some selected persian walnut (Juglans regia L.) International Journal of Agronomy and Plant Production, 4(9): 2438-2445.

Noumi E., Snoussi M., Trabelsi N., Ksouri R., Hamdaoui G., Bouslama L., Bakhrouf A. (2012): Antioxidant activities and reversed phase-high performance liquid chromatography (RP-HPLC) identification of polyphenols in the ethyl acetate extract of Tunisian Juglans regia L. treated barks. Journal of Medicinal Plants Research, 6(8): 1468-1475.

Oliveira I., Sousa A., Ferreira I.C., Bento A., Estevinho L., Pereira A. J. (2008): Total phenols, antioxidant potential and antimicrobial activity of walnut (Juglans regia L.) green husks. Food and chemical toxicology, 46(7): 2326-2331.

Pereira A.J., Oliveira I., Sousa A., Valentảo P., Andrade P.B., Ferreira I.C., Ferreres F., Bento A., Seabra R., Estevinho L. (2007): Walnut (Juglans regia L.) leaves: Phenolic compounds, antibacterial activity and antioxidant potential of different cultivars Food and Chemical Toxicology, 45(11): 2287-2295.

Saeed M., Naser S., Bahare M. (2015): Indetification of potential antioxidant compounds in Walnut (Juglans regia L.) leaves extract by multivariate calibration techniques and HPLC-DAD-MS. 5th Iranian Biennial Chemometrics seminar, Chemistry Faculty, 25-26 November, University of Teheran, Teheran, Iran.

Shah T.I., Sharma E., Shah G.A. (2015): Anti-proliferative, cytotoxicity and anti-oxidant activity of Juglans regia extract. American Journal of Cancer Prevention, 3(2): 45-50.

Solar A., Colarič M., Hudina M., Štampar F. (2006): Phenolic content of walnut fruit as affected by cultivar and developmental stage Acta Horticulturae, 705(28): 231-240.

Stampar F., Solar A., Hudina M., Veberic R., Colaric M. (2005): Traditional walnut liqueur - cocktail of phenolics. Food Chemistry, 95(2006): 627-631.

Sun B., Ricardo-Da-Silva J.M., Spranger I. (1998): Critical factors of vanillin assay for catechins and proanthocyanidins. Journal Agricultural Food Chemistry, 46(10): 4267-4274. 
Taha N. A. \& Al-Wadaan M. A. (2011): Utility and importance of walnut, Juglans regia. African Journal of Microbiology Research, 5(32): 5796-5805.

Upadhyay V., Kambhoja S., Harshaleena K. (2010): Antifungal activity and preliminary phytochemical analysis of stem bark extracts of Juglans regia linn. International Journal of Pharmaceutical \& Biological Archives, 1(5): 442-447.

Wianowska D., Garbaczewska S., Cieniecka-Roslonkiewicz A., Dawidowicz A.L., Jankowska A. (2016): Comparison of antifungal activity of extracts from different Juglans regia cultivars and juglone. Microbial Pathogenesis, 100: 263-267.

Submitted: 12.2 .2020

Accepted: 27.2 .2020 . 